\title{
EDITORIAL
}

\section{LOS ALIMENTOS MODIFICADOS GENÉTICAMENTE Y LA EPIDEMIOLOGÍA ACTUAL}

\section{María José Tormo Díaz}

Servicio de Epidemiología. Consejería de Sanidad y Consumo de la Región de Murcia.

Hasta ahora la epidemiología ha tenido que vencer importantes limitaciones a la hora de hacer extensivo su campo de actuación a exposiciones poco convencionales o nuevas. Estas limitaciones han sido, sobre todo, de tipo técnico. ¿Cómo evaluar exposiciones para las que sólo se cuenta con medios analíticos pobremente desarrollados? ¿Cómo medir las radiaciones electromagnéticas, la dieta de las personas a lo largo de la vida, los múltiples productos en los que se descomponen las fuentes de contaminación ambiental? Hay muchas razones para explicar estas limitaciones. Sin ánimo de ser exhaustiva apuntaré tres. Primera, hasta ahora se conocía poco del efecto de ciertas exposiciones crónicas sobre la salud. Segunda, los problemas de hace décadas -enfermedades respiratorias, infecciosas, malnutrición, etc.- requerían todo el esfuerzo y la inteligencia de una rama de la salud pública, la epidemiología, crónicamente mal dotada. Tercera, la opinión pública estaba menos preparada para evaluar críticamente el ambiente que la rodeaba. Imaginemos, por ejemplo, que en la década de los años 40 se hubiera sospechado que cl tabaco inhalado pudiera producir algún tipo de problema respiratorio grave. $\mathrm{Al}$ fin y al cabo era una exposición —en su forma masiva - nueva, desconocida. $Y$ que en esos años hubiera habido la suficiente disponibili-

Correspondencia:

$\mathrm{M}^{2}$ José Tormo Díaz

Servicio de Epidemiología

Avda de Ronda de Levante, 11

30008 Murcia

Correo electrónico: mjose.tormo@carm.es dad humana y técnica para recoger de forma sistemática la información sobre ventas de tabaco al mismo tiempo que la incidencia y la mortalidad por cáncer. $Y$ que hubiera sido posible medir la exposición ambiental al tabaco. Por último, imaginemos que la opinión publica hubiera insistido en discutir, a través de los medios de comunicación y de las autoridades sanitarias, las consecuencias de esta exposición. Posiblemente Doll y Peto ${ }^{1}$ hubieran podido adelantar una década sus descubrimientos y todo el movimiento crítico que ha generado el tabaco, su venta y consumo masivos - juicios, compensación de daños individuales, pactos multimillonarios para financiar la sanidad, etc. - hubieran ayudado, sino a parar la epidemia sí a reducir su onda expansiva. Si esta acción puede ahora ser llevada a cabo por la Directiva de la Unión Europea sobre el control riguroso de la publicidad del tabaco en sus estados miembros lo cierto es que se ha necesitado excesivo tiempo, información y rigor para poder tratar de cambiar el curso de una exposición tan arraigada, actualmente, en la conducta individual de muchas personas y sobre la que se mueve una espesa red de intereses. La enseñanza que se desprende es que es tarea de titanes reducir exposiciones introducidas masivamente en la población antes de estar poco o nada evaluadas desde el punto de vista de la salud pública.

La revolución tecnológica de las últimas décadas ha producido nuevos valores de utilidad incuestionable -informática, telecomunicaciones, procesos productivos- que son fuente, al mismo tiempo, de nuevas exposicio- 
nes de naturaleza desconocida para la salud. Pero ahora los avances técnicos permiten tam= bién, si se desea, realizar un acúmulo ordenado de información que permita monitorizar tanto las nuevas exposiciones como las formas - nuevas o viejas - de enfermar. Es el momento de utilizar estos avances, de forma integrada, para el progreso social.

Los alimentos modificados genéticamente (por extensión, los organismos modificados genéticamente) son el último fruto -todavía inmaduro- de ésta evolución tecnológica. $\mathrm{Su}$ conocimiento es incipiente e incompleto; está basado en la manipulación del genoma, hasta ahora un gran desconocido y del que saber mucho más que ayer no proporciona muchas certezas ni garantías porque, siendo sinceros, todavía seguimos ignorando casi todo de él; hemos identificado los genes pero no para qué sirven; tampoco sabemos que efecto, a largo plazo, puede tener insertar, activar o desactivar genes en especies no emparentadas; desconocemos el efecto de lanzar al medio ambiente nuevas formas de vida, libres para autoperpetuarse, aunque sea con ligeros cambios de su estructura nuclear. Mientras puedo compartir el optimismo de que toda esta tecnología ha resuelto ciertos problemas $y$, globalmente, pueda llegar a ser útil, mi preocupación se dirige más hacia la no utilización de las ventajas que la tecnología nos proporciona HOY para vigilar, contrastar y probar los efectos de esta innovación sobre la salud.

Los alimentos nuevos, más aún sí están producidos en base a una tecnología desconocida y con consecuencias difícilmente valorables a priori, deben ser probados en estudios experimentales antes de su puesta en circulación para consumo masivo. Esta es una metodología bien desarrollada, contrastable y que cuenta con legitimidad. Sus resultados ayudan a disipar dudas a administradores, medios de comunicación y consumidores. Aunque sólo sirve para valorar efectos agudos y a corto plazo, al menos puede evitar el desarrollo de alergias y sugerir, por ejemplo, que se están generando resistencias bacterianas con más rapidez de lo esperable. Este último es uno de los más graves problemas que pueden provocar a corto plazo ${ }^{2}$.
Los estudios experimentales con alimentos modificados genéticamente se pueden llevar a cabo tanto en diferentes tipos de animales como en seres humanos voluntarios. Lo primero que llama la atención en la introducción de esta novedad tecnológica es la práctica ausencia de estudios experimentales publicados en revistas que sean accesibles tanto a científicos como a consumidores. Pero estos estudios no son tan difíciles de hacer, ni tan caros, ni tan peligrosos. Este número de la Revista Española de Salud Pública presenta una revisión ${ }^{3}$ somera sobre la bibliografía accesible en MEDLINE ${ }^{\mathbb{B}}$ y TOXICLINE $^{\circledR}$. Y la conclusión es que es prácticamente inexistente. Por otra parte, una de las nuevas terminologías acuñadas en este campo es la de equivalencia sustancial, en la que la seguridad de un producto se compara con la de otro producido de forma natural. Este enfoque desarrollado por la OMS/OCDE parece que para muchos expertos sería el aceptable. Dada la equivalencia sustancial se han liberado voluntariamente varias especies de alimentos genéticamente modificados al medio ambiente. Si aceptamos esta línea pragmática de evaluación sería, entonces, deseable que se realizaran ensayos aleatorios controlados con voluntarios sanos para demostrar que, a corto y medio plazo, se confirma que son inocuos para la salud. Tan sólo he encontrado un ensayo experimental controlado realizado en voluntarios sanos ${ }^{4}$, aunque el hallazgo ha sido casual, ya que en las palabras clave no incluía ninguna referencia a los aspectos genéticos. En breve, se trataba de valorar si, efectivamente, un maíz modificado genéticamente para permitir una absorción mayor de hierro lo hacía. El estudio incluye a 14 personas voluntarias sanas y el protocolo fue aprobado por el comité de ética de las Universidades de Davis y de Berkeley, ambas en California. El estudio, publicado en 1998, es muy interesante porque marca una pauta a promover. La pregunta es ¿por qué no hay más estudios de este tipo publicados?

Si se acuerda que es científicamente deseable y técnicamente posible realizar estudios experimentales para evaluar efectos a corto plazo ¿qué se debería hacer para evaluar los efectos a largo plazo que, aunque puedan ser extremadamente raros, pueden alcanzar el 
punto crítico de ser capaces de detectarse y asociarse estadísticamente a la exposición? En epidemiología (por ejemplo, en farmacoepidemiología) se suelen implementar sistemas de vigilancia y monitorización. En la actualidad el progreso técnico permite realizar este tipo de vigilancia. En España y otros países occidentales existen excelentes sistemas de vigilancia de cáncer, mortalidad, malformaciones, etc. También existen redes de monitorización ambiental, de farmacovigilancia, de comunicación rápida de alimentos problemáticos para la salud, etc. Parece que es necesario poder monitorizar también la exposición a los alimentos modificados genéticamente. En realidad, para este fin no se necesitan tantos medios. Es esencial, eso sí, que los productos estén - todosetiquetados correctamente y que sean trazables o localizables. Y desde luego, en una globalización económica el sistema de vigilancia debe unificarse en criterios y coberturas. Algunos países ya lo están valorando aunque no hay todavía respuestas ${ }^{5}$. Actualmente las multinacionales pueden notificar por todos los medios de comunicación que una de sus partidas ha tenido defectos de producción, debe retirarse del mercado y así evitar cuanto antes la extensión del problema (ej. las dioxinas en los pollos belgas, la carne de vacuno inglés y la variante de la enfermedad de CreutfeldJakob, etcétera.). Esta acción es factible, se hace, controla la expansión del problema y restablece la confianza pública en los mecanismos administrativos de seguridad alimentaria.

Una vez introducidos los dos elementos clave de la vigilancia de los alimentos modificados genéticamente quiero hacer referencia a una pregunta habitual. ¿Por qué los alimentos modificados genéticamente se perciben de forma diferente a otros productos, sobre todo de uso farmacológico, ampliamente aceptados y que también se han producido mediante cambios en el genoma del organismo natural? Las vacunas, los antibióticos, los injertos de tejido, los medios de detección precoz, etc., se han beneficiado mucho de la introducción de esta tecnología y podemos considerarlos como un preciado bien para la salud de la población. Pero mientras para estos productos ha habido una necesidad sentida por parte de la población (mejores antibióticos, pautas de administra- ción de insulina más adecuadas, vacunas baratas e inocuas) que los reconoce y los valora, los alimentos modificados genéticamente han aparecido inesperadamente en los países más desarrollados, sin percepción alguna de su necesidad, sin evidencias claras de sus ventajas nutritivas, con una desconcertante cobertura de información pública -incluyendo las largas polémicas sobre el etiquetado-, y sin ninguna autoridad sanitaria reconociendo ampliamente sus ventajas, su seguridad, su inocuidad.

La percepción de los riesgos por parte de la población no se basa en valoraciones arbitrarias y fluctuantes, como bien muestran los trabajos de varios autores americanos ${ }^{6-8}$ que durante las pasadas décadas evaluaron en trabajos científicamente válidos, que las personas estudiadas eran capaces de priorizar sus sensaciones de riesgo, que éstas eran ordenadas similarmente al repetir los estudios y que eran lo suficientemente homogéneas como para sugerir determinados patrones que podían ser generalizables a grupos de población más amplios. Así, los riesgos que más temor producen son ${ }^{9}$ los que: 1 . son involuntarios; 2 . se distribuyen de tal forma que benefician mucho a unas pocas personas mientras que otras muchas son las que pueden sufrir las consecuencias; 3 . los que no se pueden evitar ni tomando precauciones personales; 4 . los que provienen de fuentes nuevas y poco entendidas por la ciencia; 5 . los que son producidos por la manipulación del hombre en vez de provenir de fuentes naturales; 6 . los que pueden producir daños en las generaciones venideras (por. ej. en niños, embarazadas, etc.). Este tipo de riesgos se temen más que los que son voluntarios, independientemente de los tóxicos que se haya demostrado que puedan llegar a ser.

El principal daño que se puede sufrir, al no tener en consideración estas percepciones o tratarlas como fruto del desconocimiento o el capricho, es la pérdida de la confianza de los ciudadanos en sus organismos reguladores, muy difícil de restablecer, como muestra bien el caso de Inglaterra, posiblemente en este momento una de las ciudadanías más escépticas del mundo y donde para cada 
nuevo problema que tenga que ver con la alimentación se tienen que crear comisiones independientes de evaluación. El gobierno, principalmente las autoridades sanitarias y agrícolo-ganaderas, han tenido que aprender la severa lección de perder el crédito de la confianza.

Y aquí viene el nexo con la epidemiología actual, tal como la percibo, que creo que hay que empezar a comunicar. Ésta impulsa la medición de las nuevas exposiciones así como amplía y mejora algunas de las ya conocidas; realiza su contraste periódico con la evolución de la frecuencia de las enfermedades; está preparada para integrar información de fuentes muy distintas (integrative assessment) y piensa en la salud del ciudadano al mismo tiempo que en la salud de su entorno. Al fin y al cabo, el ser humano no es diferente - sino interdependiente - de lo que le rodea. La epidemiología actual exige avances técnicos también en la medición de las nuevas exposiciones, reclama inversiones suficientes en investigación epidemiológica de los nuevos riesgos y defiende, junto a las organizaciones de consumidores, el derecho de los ciudadanos a elegir libre e informadamente sus alimentos, su entorno, las exposiciones a las que voluntariamente se somete. La epidemiología actual sabe comunicar los riesgos a la población de una forma clara, incluyendo la incertidumbre y el desconocimiento. Son nuevos retos para un nuevo tiempo y la epidemiología actual ha de mostrar su liderazgo e iniciativa.

\section{BIBLIOGRAFÍA}

1. Doll R, Peto R. Mortality in relation to smoking: 20 years' observations on male British doctors. Br Med J 1976; 2:1525-1536.

2. Amyes SG. The rise in bacterial resistance (editorial). BMJ 2000; 320:199-200.

3. Domingo Roig J L y Gómez Arnáiz M. Riesgos sobre la salud de los alimentos modificados genéticamente: una revisión bibliográfica. Rev Esp de Salud Pública 2000;74: 225-261.

4. Mendoza C, Viteri FE, Lonnerdal B, Young KA, Raboy V, Brown KH. Effect of genetically modified, low-phytic acid maize on absorption of iron from tortillas. Am $\mathbf{J}$ Clin Nutr 1998; 68:1123-1127.

5. Donaldsom L, May R. Health implications of genctically modified foods. [citado 12 oct. 2000] http://www.doh.gov.uk/gmfood.htm.

6. Fischhoff B, Slovic P, Lichtenstein S, Read S, Coombes B. How safe is safe enough? A psychometric study of attitudes towards technological risks and bencfits. Policy Sciences 1978;9:127-2.

7. Slovic P. Informing and educating the public about risk. Risk Analysis 1986;6:403-15.

8. Gardner GT, Gould LC. Public perceptions of the risk and benefits of technology. Risk Analysis 1989;9:225-42.

9. Bennett P \& Calman K (eds). Risk communication and public health. Oxford New York: Oxford University Press, 1999 pg:6-7. 